\title{
Surface functionalization of germanium ATR devices for use in FTIR-biosensors
}

\author{
Sabrina Devouge ${ }^{a}$, Joséphine Conti ${ }^{b}$, Andréa Goldsztein ${ }^{c}$, Emmanuel Gosselin $^{\mathrm{b}}$, Alain Brans ${ }^{\mathrm{d}}$, Michel Voué ${ }^{\mathrm{b}}$, \\ Joël De Coninck ${ }^{\mathrm{b}}$, Fabrice Homblé ${ }^{\mathrm{c}}$, Erik Goormaghtigh ${ }^{\mathrm{c}}$, Jacqueline Marchand-Brynaert ${ }^{\mathrm{a}, *}$ \\ a Unité de Chimie Organique et Médicinale, Université Catholique de Louvain, Bâtiment Lavoisier, Place Louis Pasteur 1, B-1348 Louvain-la-Neuve, Belgium \\ b Centre de Recherche en Modélisation Moléculaire, Université de Mons-Hainaut, Parc Initialis, Avenue Copernic 1, B-7000 Mons, Belgium \\ ${ }^{\mathrm{c}}$ Laboratoire de Structure et Fonction des Membranes Biologiques, Centre de Biologie Structurale et Bio-informatique, Université Libre de Bruxelles, Campus Plaine CP206/2, \\ B-1050 Bruxelles, Belgium \\ d Centre d'Ingénierie des Protéines, Université de Liège, Bâtiment B6, Allée de la Chimie, B-4000 Sart-Tilman, Belgium
}

\section{A R T I C L E I N F O}

\section{Article history:}

Received 12 September 2008

Accepted 17 December 2008

Available online 24 December 2008

\section{Keywords:}

Germanium

ATR crystal

FTIR biosensors

Thin film

Phenyl azide

Photografting

BlaR-CTD protein

Non-fouling surface

\begin{abstract}
A B S T R A C T
Biosensors based on intrinsic detection methods have attracted growing interest. The use of Fourier transform infra-red (FTIR) spectroscopy with the attenuated internal total reflection (ATR) mode, in the biodetection context, requires appropriate surface functionalization of the ATR optical element. Here, we report the direct grafting of a thin organic layer (about $20 \AA$ depth) on the surface of a germanium crystal. This covering, constructed with novel amphiphilic molecules $2 \mathbf{b}$ (namely, 2,5,8,11,14,17,20-heptaoxadocosan-22-yl-3-(triethoxysilyl) propylcarbamate), is stable for several hours under phosphate buffered saline (PBS) flux and features protein-repulsive properties. Photografting of molecule $\mathbf{5}$ (namely, O-succinimidyl 4-( $p$-azidophenyl)butanoate) affords the activated ATR element, ready for the covalent fixation of receptors, penicillin recognizing proteins BlaR-CTD for instance. The different steps of the previous construction have been monitored by water contact angle $\left(\theta_{\mathrm{w}}\right)$ measurements, spectroscopic ellipsometry (covering depth), X-ray photoelectron spectroscopy (XPS) by using a fluorinated tag for the control of surface reactivity, and FTIR-ATR spectroscopy for the structural analysis of grafted molecules. Indeed, contrarily to silicon device, germanium device offers a broad spectral window $\left(1000-4000 \mathrm{~cm}^{-1}\right)$ and thus amide I and II absorption bands can be recorded. This work lays the foundations for the construction of novel FTIR biosensors.
\end{abstract}

(C) 2008 Elsevier Inc. All rights reserved.

\section{Introduction}

Label free detection of "ligand-receptors" interaction at the surface of a device has become the subject of growing interest, in connection with the development of biosensors [1,2]. Amongst the reliable detection methods [3-5], surface infrared spectroscopy (FTIR-ATR, Fourier transform infrared using the attenuated total internal reflection mode) offers the advantage of coupling the detection with the collect of structural information about interacting partners [6,7]. We have already described a new type of biosensor, called BIA-ATR [8], based on a functionalized ATR germanium crystal and the detection of "ligand-receptor" interactions in aqueous media, at the water-device interface, by FTIR spectroscopy. For instance, the ATR element was hydrophobized by reaction with octadecyltrichlorosilane (OTS) under adapted wet-chemistry conditions and then coated with phospholipid membranes fragments containing a few percents of phosphatidylserine as receptors. This

\footnotetext{
* Corresponding author. Fax: +32 10474168 .

E-mail address: jacqueline.marchand@uclouvain.be (J. Marchand-Brynaert).
}

device allowed the specific detection of coagulation factor VIII in the presence of a large excess of other proteins [9].

We are now interested in the covalent grafting of receptors (mainly proteins) on the surface of ATR elements in view to detect low molecular weight ligands. The mostly used ATR crystals are made of silicon; the material is quite inexpensive and the surface chemistry of silicon has been widely described [10]. However, a problem of silicon, not encountered with germanium, is its opacity below $1550 \mathrm{~cm}^{-1}$ [11]. Yet, the fingerprint region of organic molecules below $1550 \mathrm{~cm}^{-1}$ is essential for univocal structure assignment. Therefore, BIA-ATR biosensor includes preferably a germanium optical element. Due to the cost of germanium and its enhanced sensitiveness comparatively to silicon versus surface degradation [12-14], the crystal preparation for the covalent anchorage of a biomolecule of interest has been carefully examined.

The requirements of this organic covering are as follows: (i) easiness and reproducibility of the surface chemistry; (ii) receptor (biomolecule) fixation via a tunable functionalization method; (iii) selectivity versus the (non-covalent) adsorption of biomolecules; (iv) stability versus chemical hydrolysis under physiological condi- 
tions (phosphate buffered saline (PBS) for instance); (v) simple conditions of storage and multi-use.

In this paper, we describe the design, the synthesis, and the validation of an organic layer which meets all the above conditions. Our strategy has been first established on silicon ATR elements, and then successfully applied to germanium. The different steps of the construction were surface-analyzed by X-ray photoelectron spectroscopy (XPS), while the stability and selectivity were assayed by FTIR-ATR analysis.

\section{Materials and methods}

\subsection{Materials}

ATR crystals were silicon or germanium internal reflexion elements (IRE) $\left(50 \times 20 \times 2 \mathrm{~mm}^{3}\right)$ with an internal incidence angle of $45^{\circ}$ (ACM, Villiers St Frédéric, FR).

The molecular clip 5 (O-succinimidyl 4-( $p$-azidophenyl)butanoate) was prepared according to reference [15]. PEG molecules 1a and 1b (2-[methoxy(polyethyleneoxy)propyl]trimethoxysilane and trichlorosilane, 90\%) were purchased from ABCR (Germany). Complete procedure for the preparation of PEG molecule $\mathbf{2 b}$ and its spectroscopic characterization are provided as supplementary material.

Phosphate-buffered saline (PBS) solution at $\mathrm{pH} 7.4$ was prepared from $\mathrm{NaH}_{2} \mathrm{PO}_{4}(0.26 \mathrm{~g})$, and $\mathrm{Na}_{2} \mathrm{HPO}_{4}$ (1.146 g) in MilliQ water $(100 \mathrm{~mL})$ containing $0.9 \% \mathrm{NaCl}$.

BlaR-CTD protein, generously furnished by Prof. Bernard Joris (Centre d'Ingénierie des protéines, Université de Liège, Belgium), was used in a concentration of $300 \mu \mathrm{g} / \mathrm{mL}$ in PBS at pH $8(20 \mathrm{mM}$ $\mathrm{NaH}_{2} \mathrm{PO}_{4}$ and $250 \mathrm{mM} \mathrm{NaCl}$ ).

\subsection{Methods}

Advancing contact angles of MilliQ water drops $\left(\theta_{\mathrm{w}}\right)$ were measured using a custom-built gionometer with an analogue camera as described in reference [8].

The thickness of the grafted layers was determined by spectroscopic ellipsometry. The measurements were carried out with a GESP5 rotating polarizer instrument operated in scanning mode, with a spectral resolution of $5 \mathrm{~nm}$. The ellipsometer was operated in parallel beam configuration at three angles of incidence: $65^{\circ}$, $70^{\circ}$ and $75^{\circ}$. The polarizer rotated at $9 \mathrm{~Hz}$ and the analyzer angle was adjusted at each wavelength, according to a tracking procedure.

XPS spectra were recorded on a Kratos Axis Ultra spectrometer (Kratos Analytical, Manchester, UK) equipped with a monochromatized aluminium X-ray source (powered at $10 \mathrm{~mA}$ et $15 \mathrm{kV}$ ). The pressure in the analysis chamber was around $10^{-6} \mathrm{~Pa}$. The angle between the normal to the sample surface and the lens axis was $0^{\circ}$. The hybrid lens magnification was used with the slot aperture and the iris drive position set at 0.5 resulting in an analysed area of $700 \mu \mathrm{m} \times 300 \mu \mathrm{m}$. The constant pass energy of the hemispherical analyser was set at $40 \mathrm{eV}$. In these conditions, the energy resolution gives a full width at half maximum (FWHM) of the $\mathrm{Ag}_{3 \mathrm{~d}_{5 / 2}}$ peak of about $1.0 \mathrm{eV}$. Charge stabilization was achieved by using the Kratos Axis device. The binding energies were calculated with respect to the $\mathrm{C}-(\mathrm{C}, \mathrm{H})$ component of the $\mathrm{C}_{1 \mathrm{~s}}$ peak fixed at $284.8 \mathrm{eV}$. Data treatments were done with the CasaXPS program (Casa Software Ltd, UK) with a Gaussian/Lorentzian (70/30) product function and after subtraction of a linear baseline.

FTIR-ATR spectra were obtained on a Bruker IFS 55 FTIR spectrophotometer (Ettlingen, Germany) equipped with a MCT detector (broad band $12000-420 \mathrm{~cm}^{-1}$, liquid $\mathrm{N}_{2}$ cooled, $24 \mathrm{~h}$ hold time) at a resolution of $2 \mathrm{~cm}^{-1}$ with an aperture of $3.5 \mathrm{~mm}$ and acquired in the double-sided, forward-backward mode. The experimental details were described in reference [8]. The software used for data processing was written in MatLab 7.1 (Mathworks Inc, Natik, MA).

\subsection{Surface chemistry}

Silicon crystals were washed with chloroform $(2 \times 5 \mathrm{~min})$ under sonication, and then submitted to UV-ozone treatment $(2 \times 10 \mathrm{~min}$, on each face). Oxidation was performed with $95 \% \mathrm{H}_{2} \mathrm{SO}_{4} / 30 \% \mathrm{H}_{2} \mathrm{O}_{2}$ $(70 / 30, v / v)$ during $10 \mathrm{~min}$ at $110-130^{\circ} \mathrm{C}$. The devices were abundantly rinsed with MilliQ water and dried under $\mathrm{N}_{2}$ flux $(17 \mathrm{~h})$.

Germanium crystals were washed with $38 \% \mathrm{HNO}_{3}(1 \mathrm{~min}$ ) and rinsed with MilliQ water. Oxidation was performed with $99+\%$ oxalic acid $/ 35 \% \mathrm{H}_{2} \mathrm{O}_{2}(10 / 90, \mathrm{v} / \mathrm{v})$ during $5 \mathrm{~min}$ at $20^{\circ} \mathrm{C}$, and washing with MilliQ water. This was repeated three times. The devices were dried under $\mathrm{N}_{2}$ flux (17 h).

The grafting protocol of silanes $(\mathbf{1 a}, \mathbf{1 b}, \mathbf{2 b})$ was the same for $\mathrm{Si}-\mathrm{OH}$ and $\mathrm{Ge}-\mathrm{OH}$ surfaces. The crystals were immersed into $2 \%$ PEG solutions in $\mathrm{CCl}_{4}$, under $\mathrm{N}_{2}$ atmosphere, during $3 \mathrm{~h}$ at reflux. The crystals were washed with methanol $(2 \mathrm{~h})$ and with tetrahydrofuran $(2 \mathrm{~h})$ in a soxhlet apparatus. The resulting surfaces are named Si-PEG 1a, Si-PEG 1b, Si-PEG 2b and Ge-PEG 1a, Ge-PEG 1b, Ge-PEG 2b, respectively.

The photografting of azide $\mathbf{5}$ on Si-PEGs and Ge-PEGs was performed similarly. A solution of molecular clip 5 in benzene $(5 \mathrm{mg} /$ $1.5 \mathrm{~mL}$ ) was sprayed on the device and the solvent was evaporated under air flux in the dark (deposition of 0.1 to $0.2 \mathrm{mg} \mathrm{5/}$ $\mathrm{cm}^{2}$ ). The device was submitted to UV irradiation during $2 \mathrm{~h}$ at room temperature (3 lamps of $8 \mathrm{~W}$ and $\lambda_{\mathrm{m}} 254 \mathrm{~nm}$, placed at a distance of $10 \mathrm{~cm})$. The device was rinsed with THF (10 min) and $\mathrm{CHCl}_{3}(5 \mathrm{~min})$ under shaking at $20^{\circ} \mathrm{C}$ (Edmund Bühler stirrer, model KL-2, $150 \mathrm{rpm})$. The resulting surfaces are named Si-PEGNHS and Ge-PEG-NHS. The blank sample was similarly prepared, but with omitting the irradiation.

The covalent coupling of the amine 6 (fluorinated tag $=3,5$ bis(trifluoromethyl)benzylamine) was performed similarly on SiPEG-NHS and Ge-PEG-NHS. The device was immersed into a solution of 6 in $\mathrm{CH}_{2} \mathrm{Cl}_{2}(0.2 \mathrm{~g} / 250 \mathrm{~mL})$, under argon atmosphere for $2 \mathrm{~h}$, at reflux. The device was rinsed with $\mathrm{CH}_{3} \mathrm{CN}(2 \times 10 \mathrm{~min})$ at $20^{\circ} \mathrm{C}$ under shaking $(150 \mathrm{rpm})$. The resulting surfaces are named Si-PEG-F6 and Ge-PEG-F6.

\subsection{Fixation/adsorption of proteins}

A solution containing the receptor (BlaR-CTD protein) was passed over the ATR crystal for $3 \mathrm{~h}$ with a discontinue flow of $20 \mu \mathrm{l} / \mathrm{min}$ speed. A total volume of $200 \mu \mathrm{L}$ was needed for the covalent binding of BlaR-CTD on Ge-PEG-NHS. Then the covalent binding was stabilized by passing the PBS solution for $30 \mathrm{~min}$ with a continue flow of $20 \mu \mathrm{l} / \mathrm{min}$ speed. A spectrum was recorded every $30 \mathrm{~min}$ during the binding, then every $10 \mathrm{~min}$ for the stabilisation. In this work, the spectra of biological samples were registered under medium flow, thus with an excess of water. This contribution of the medium was eliminated by subtracting of the medium spectra by a coefficient $1(100 \%)$ for all the registered spectra.

\section{Results and discussion}

\subsection{Design and synthesis of the organic reagent}

Polyethylene glycols (PEGs) are widely used to reduce nonspecific adsorption of biomolecules (proteins) on surfaces [16,17]. When chemical grafting is concerned instead of coating, oligomers of ethylene oxide (chains containing 3 to 9 EO units) are also efficient [18-20]. Surface treatment of glass and metal oxides is 


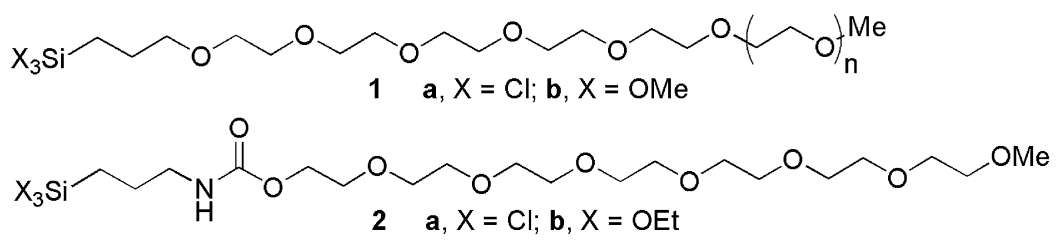

Fig. 1. Silanization reagents; $\mathbf{1}=$ commercially available compounds as mixtures with $n=1$ to $3 ; \mathbf{2} \mathbf{b}=$ home-made compound.
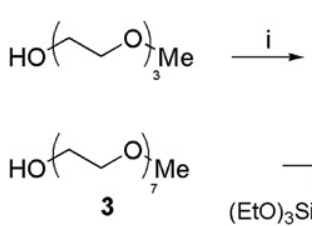

$\mathrm{Me}-\mathrm{S}_{\mathrm{O}}^{\mathrm{O}} \mathrm{O}-\mathrm{O}(\mathrm{O})_{3} \mathrm{Me}$
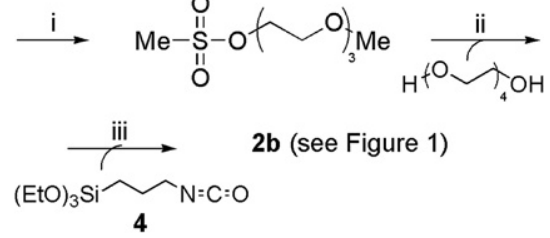

Scheme 1. Synthesis of $\mathbf{2 b}$. Reagents and conditions: (i) $\mathrm{MsCl}$, pyridine, $0^{\circ} \mathrm{C}$ to $20^{\circ} \mathrm{C}$, $20 \mathrm{~h}$; (ii) $50 \% \mathrm{NaOH}$, toluene, $100^{\circ} \mathrm{C}, 20 \mathrm{~h}$; (iii) $\mathrm{KCl}$, THF, reflux, $45 \mathrm{~h}$.

generally performed with commercial silane derivatives, such as 3[methoxy (polyethyleneoxy)] propyl trimethoxysilane or trichlorosilane (Fig. 1; 1a, 1b). In the case of oxidized silicon, the silanization reaction takes place most commonly in toluene at room temperature for several hours [21,22]. Very few studies are devoted to the stability of PEG-derivatized silicon (and none about germanium), under conditions mimicking physiological media used for biosensor detection $[23,24]$. Nevertheless, it appears that such devices are not highly stable in phosphate buffered saline (PBS) and that the loss of PEGs most probably results from basic hydrolysis of the $\mathrm{Si}-\mathrm{O}$ bonds within the interface oxide layer [25].

The problem of long-term stability of self-assembled monolayers (SAMs) in biological fluids [26] could be addressed by using amphiphilic silane derivatives for reaction on oxidized surfaces. Since the hydrolysis of PEGylated silicon is inherent to the PEG hydrophilicity, incorporation of a hydrophobic segment next to the reactive silane function would prevent the access of water molecules to the device surface. A recent publication of Yoshino [27] describes the preparation of a silicon surface featuring alkyl chains of $14 \mathrm{CH}_{2}$ units linked to $9 \mathrm{EO}$ units, in five steps from the oxidized support. This substrate showed a high waterproof durability and a good ability to suppress protein adsorption. A similar strategy was already known in the case of amphiphilic thiols used for gold surface functionalization [28-30].

In our context of FTIR-based sensor, the organic layer covering the ATR element has to be as thin as possible for optimal spectroscopic measurements. Hence, we considered the possibility of using a novel amphiphilic silanization reagent composed of a very short alkyl chain ( 3 methylene groups instead of $\geqslant 11$ ) and a short PEG chain (6 EO units are considered as the minimum length to induce the protein repulsive effect [31]), connected via a carbamate link. This key function, although relatively hydrophobic, will be able to establish hydrogen bonds between vicinal chains and, hopefully, prevent water penetration into the resulting network. Molecule 2 was designed as synthetic target in order to validate the concept (Fig. $1 ; \mathbf{2})$. Trichlorosilanes $(\mathrm{X}=\mathrm{Cl}$ ) are more reactive than trialkoxysilanes $(\mathrm{X}=\mathrm{OMe}, \mathrm{OEt})$, but also more susceptible to hydrolysis and polymerization. Therefore, in the present work, only triethoxysilane $\mathbf{2 b}$ has been considered.

The synthesis of 2,5,8,11,14,17,20-heptaoxadocosan-22-yl-3(triethoxysilyl)propylcarbamate $(\mathbf{2 b})$ is outlined in Scheme 1 . Monomethyl ether of heptaethyleneglycol (3) reacted with 3-(isocyanato)propyl triethoxysilane (4) in refluxing tetrahydrofuran; addition of potassium chloride in the reaction medium was required to reach quantitative yield. The nature of the organic layer being defined, we have to further choose the method of receptor anchorage for the biosensor device construction. We have previously disclosed a general strategy of (organic) surfaces functionalization based on the photografting of a so-called "molecular clip" [15], i.e. an arylazide derivative. Application of this strategy to PEGylated surfaces is expected to be easily done because methylenoxy groups are quite reactive under radicalar conditions [32].

\subsection{Surface chemistry on silicon}

Silicon ATR crystals were cleaned and activated (surface oxidation) as described for silicon wafers [10,33], and reacted with commercial silanes $\mathbf{1 a}$ and $\mathbf{1 b}$, and the home-made amphiphilic silane 2b using the same protocol (Scheme 2, step i). The quality of the grafted organic layer was assayed by static contact angle measurements with water $\left(\theta_{\mathrm{w}}\right)$ and FTIR-ATR spectroscopy.

From the results collected in Table 1 (entries 1 to 3 ), a problem of reproducibility clearly appeared for the silanization reaction using commercial PEGs 1a and $\mathbf{1 b}$. On the other hand, the wettability recorded when grafting silane $\mathbf{2 b}$ was more homogeneous with a $\theta_{\mathrm{w}}$ value around $52^{\circ}$. This value is consistent with the reported wettability of MeO-terminated PEG-SAM monolayer on gold $\left(\theta_{\mathrm{W}}=48.0 \pm 2^{\circ}\right.$ [34]). For sample Si-PEG $\mathbf{2 b}$, a modified interface depth of $41.5( \pm 0.6) \AA$ was determined by ellipsometry. Taking into account the depth of the oxide layer (typically, about $20 \AA$ ), the organic covering depth should correspond to about $20 \AA$, a value compatible with a monolayer, but slightly lower than the one expected on the basis of a molecular mechanics simulation of silane $\mathbf{2 b}$ (theoretical value: $28.5 \AA$ ). Remembering that spectroscopic ellipsometry averages the thickness of the layer over the size of the light spot (about $3 \times 4 \mathrm{~mm}^{2}$ ) and assuming that the tilt of the silane molecules with respect to the ATR surface does not induce additional steric constraints, one may conclude that the fraction of the surface covered by the organic layer is at least $75 \%$.

The C-H stretching region of the FTIR-ATR spectrum of Si-PEG 1b is shown in Fig. 2. The peaks found at $2956 \mathrm{~cm}^{-1}\left(\mathrm{w}, \mathrm{CH}_{3} \mathrm{st}\right.$ as), $2923 \mathrm{~cm}^{-1}$ (s, $\mathrm{CH}_{2}$ st as) and $2853 \mathrm{~cm}^{-1}$ (m, $\mathrm{CH}_{3}$ st sy) are in moderate agreement with previous theoretical works devoted to PEG-SAMs on gold and experimental measurement by infrared reflection-absorption (RA) spectroscopy [34-38]. Sample Si-PEG 2b showed similar features in the $2800-3000 \mathrm{~cm}^{-1}$ region; the carbamate $\mathrm{NH}$ stretching was also visible (broad peak at $3330 \mathrm{~cm}^{-1}$ ).

The functionalization of Si-PEG $\mathbf{2 b}$ was achieved by the photografting of O-succinimidyl 4-( $p$-azidophenyl)butanoate (5) (Scheme 2, step ii). Photo-decomposition of azide $\mathbf{5}$ generates a highly reactive nitrene species that inserts randomly into $\mathrm{C}-\mathrm{H}$ bonds of the PEG chain, while the NHS ( $N$-hydoxysuccinimidyl) moiety of the "molecular clip" remains stable under UV treatment [39]. The resulting device (Si-PEG-NHS) features activated ester functions, ready for trapping amine-terminated molecules. This surface reactivity was assayed by coupling 3,5-bis(trifluoromethyl)benzylamine (6) considered as a fluorinated tag for the XPS analysis [40]. After covalent grafting of $\mathbf{6}$ (Scheme 2, step iii), the device surface (Si-PEG-F6) was characterized by XPS, comparatively to the native device $(\mathrm{Si}-\mathrm{OH})$, and the intermediately functionalized device (Table 2). Native $\mathrm{Si}-\mathrm{OH}$ was contaminated with carbon (27\%) and nitrogen (0.9\%); Si/O atomic ratio was 0.93 (entry 1 ). After silaniza- 


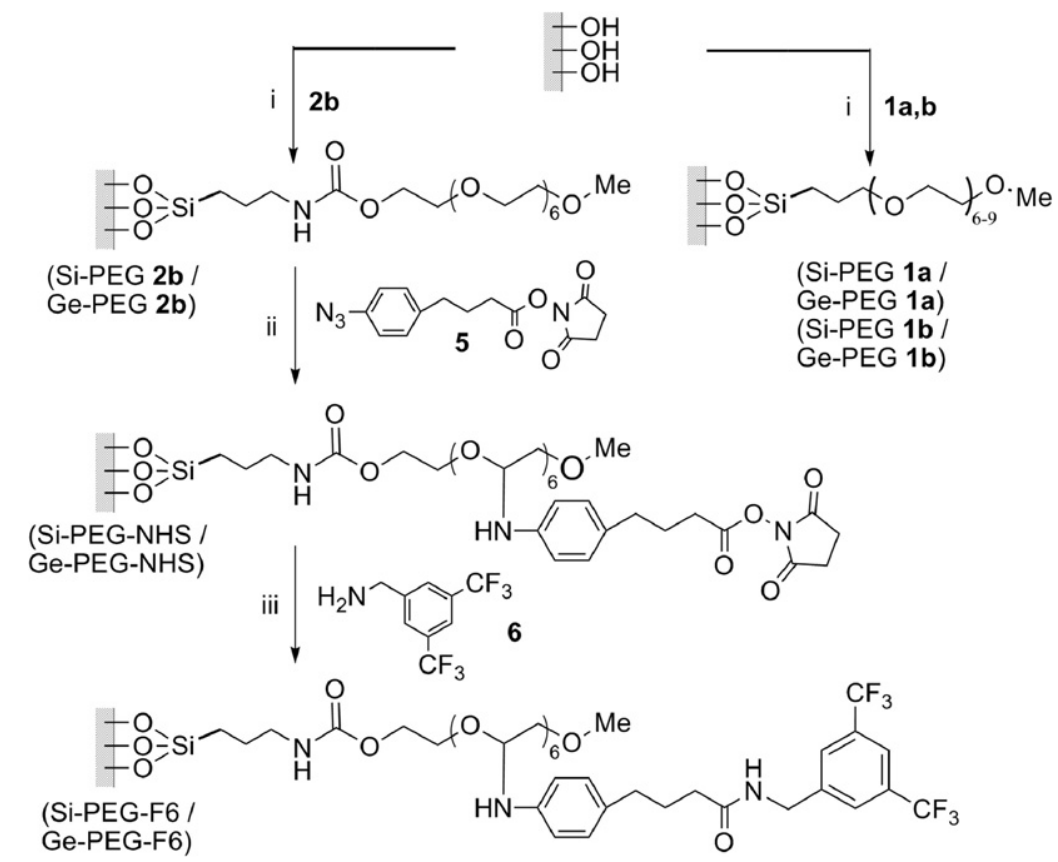

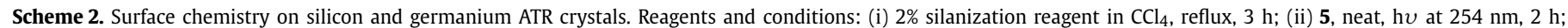
washing; (iii) $3 \times 10^{-2} \mathrm{M} 6$ in $\mathrm{CH}_{2} \mathrm{Cl}_{2}$, reflux, 2 h; washing.

Table 1

$\theta_{\mathrm{w}}$ measurements.

\begin{tabular}{lll}
\hline Entry & Sample & $\theta_{\mathrm{w}}\left({ }^{\circ}\right)^{\mathrm{a}}$ \\
\hline 1 & Si-PEG 1a & $42.8 ; 46.8 ; 39.3 ; 37.1 ; 38.4$ \\
2 & Si-PEG 1b & $38.8 ; 49.4 ; 46.8 ; 39.3 ; 38.4$ \\
3 & Si-PEG 2b & $55.1 ; 53.4 ; 52.5 ; 51.6 ; 53.1$ \\
4 & Ge-PEG 1a & $20.6 ; 39.9 ; 21.0 ; 37.5 ; 46.1$ \\
5 & Ge-PEG 1b & $43.8 ; 20.6 ; 39.9 ; 37.8 ; 37.5$ \\
6 & Ge-PEG 2b & $39.8 ; 41.2 ; 41.6 ; 41.8 ; 43.8$ \\
\hline
\end{tabular}

a Values of 5 independent preparations; each value is the mean of 20 measurements $( \pm 3)$.

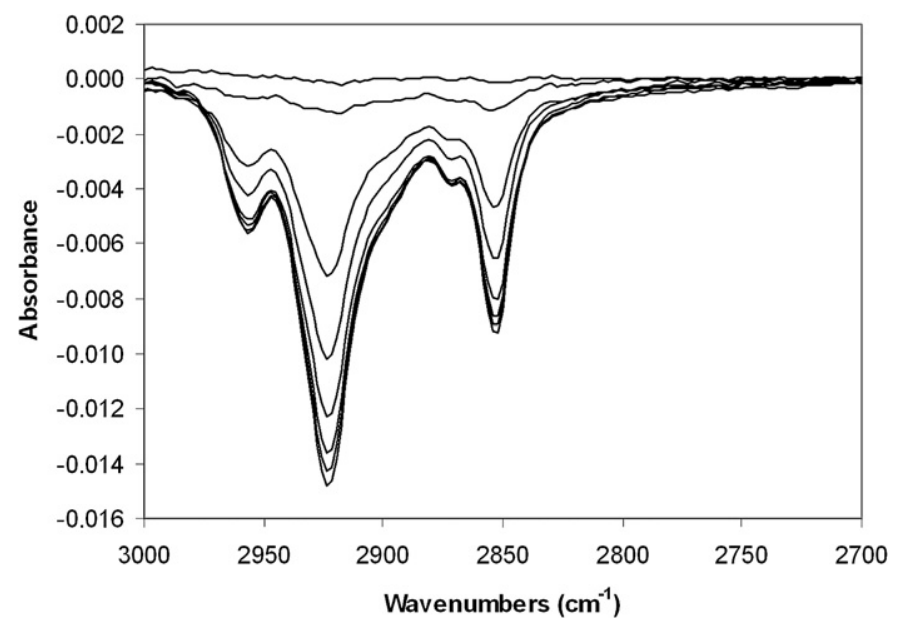

Fig. 2. ATR spectrum of Si-PEG 1b (C-H stretching region). Stability versus hydrolysis monitored as a function of time. From top to bottom: $t(\min )=3,14,48,82,116$, 150, 180, 220.

tion with $\mathbf{2 b}$, the percentages of carbon (54\%) and nitrogen (4.7\%) increased significantly (entry 2). Photo-implanting of NHS moieties further enhanced this phenomenon (entry 3). Substitution of NHS with amine $\mathbf{6}$ was attested by the presence of fluorine atoms $(1.88 \%)$ in the surface atomic composition of sample Si-PEG-F6 (entry 4). A substitution rate of about $20 \%$ has been calculated (see supplementary material).
Table 2

XPS analysis of surface functionalized Si ATR crystals.

\begin{tabular}{lllllrl}
\hline Entry & Sample & \multicolumn{6}{l}{ Elemental composition (atom\%) } \\
\cline { 3 - 7 } & & $\mathrm{C}_{1 \mathrm{~s}}$ & $\mathrm{O}_{1 \mathrm{~s}}$ & $\mathrm{~N}_{1 \mathrm{~s}}$ & \multicolumn{1}{c}{$\mathrm{Si}_{2 \mathrm{p}}$} & $\mathrm{F}_{1 \mathrm{~s}}$ \\
\hline 1 & Si-OH & 27.38 & 37.14 & 0.89 & 34.58 & $/$ \\
2 & Si-PEG 2b & 54.46 & 32.02 & 4.68 & 8.85 & $/$ \\
3 & Si-PEG-NHS & 61.17 & 25.20 & 6.06 & 7.57 & $/$ \\
4 & Si-PEG-F6 & 54.75 & 26.05 & 4.43 & 12.88 & 1.88 \\
\hline
\end{tabular}

\subsection{Surface chemistry on germanium}

Although the chemical binding of molecules on silicon substrates via the surface $\mathrm{Si}-\mathrm{OH}$ groups has been widely exploited, less studies are devoted to germanium [13], most probably because the germanium oxide layer is water soluble, contrarily to the silicon one. Ge surface is poorly resistant to the oxidative pretreatment required for increasing the amount of reactive $\mathrm{Ge}-\mathrm{OH}$ groups. We previously demonstrated that smooth surface oxidation of Ge ATR element could be performed by treatment with $\mathrm{H}_{2} \mathrm{O}_{2}$ and oxalic acid [8]. Silanization with commercial PEGs 1a and 1b was conducted as for Si ATR element (Scheme 2, step i). As shown in Table 1 , the water contact angles measured on five series of samples gave scattered values, from $20^{\circ}$ to $46^{\circ}$ (entries 4-5). The reproducibility of the grafting protocol appeared even more difficult to master than in the case of silicon. However, by using the home-made silane $\mathbf{2 b}$, we obtained surface-modified elements with $\theta_{\mathrm{w}}$ values ranging between $40^{\circ}$ and $44^{\circ}$ (entry 6). The thickness of the organic layer of Ge-PEG $\mathbf{2} \mathbf{b}$, measured by ellipsometry, was similar to that of Si-PEG $\mathbf{2 b}$ sample.

FTIR-ATR spectra of samples Ge-PEG 1a and Ge-PEG 2b (elements with similar $\theta_{\mathrm{w}}$ of $\pm 40^{\circ}$ ) are compared in Fig. 3. Thanks to the wide spectral window offered by the germanium optical element, analysis could be now performed in the $900-4000 \mathrm{~cm}^{-1}$ domain. The acceptable reproducibility of the surface chemistry is shown by the spectra (a) and (b) of two samples similarly treated (Fig. 3). Ge-PEG 1a sample showed broad bands at $2938 \mathrm{~cm}^{-1}$ and $2871 \mathrm{~cm}^{-1}\left(\mathrm{CH}_{2}\right.$ asymmetric and symmetric stretching, respectively), more typical of disordered ethylene oxide (EO) methylene groups than oriented SAMs of $(\mathrm{EO})_{n}$ [34-38]. In the fingerprint 


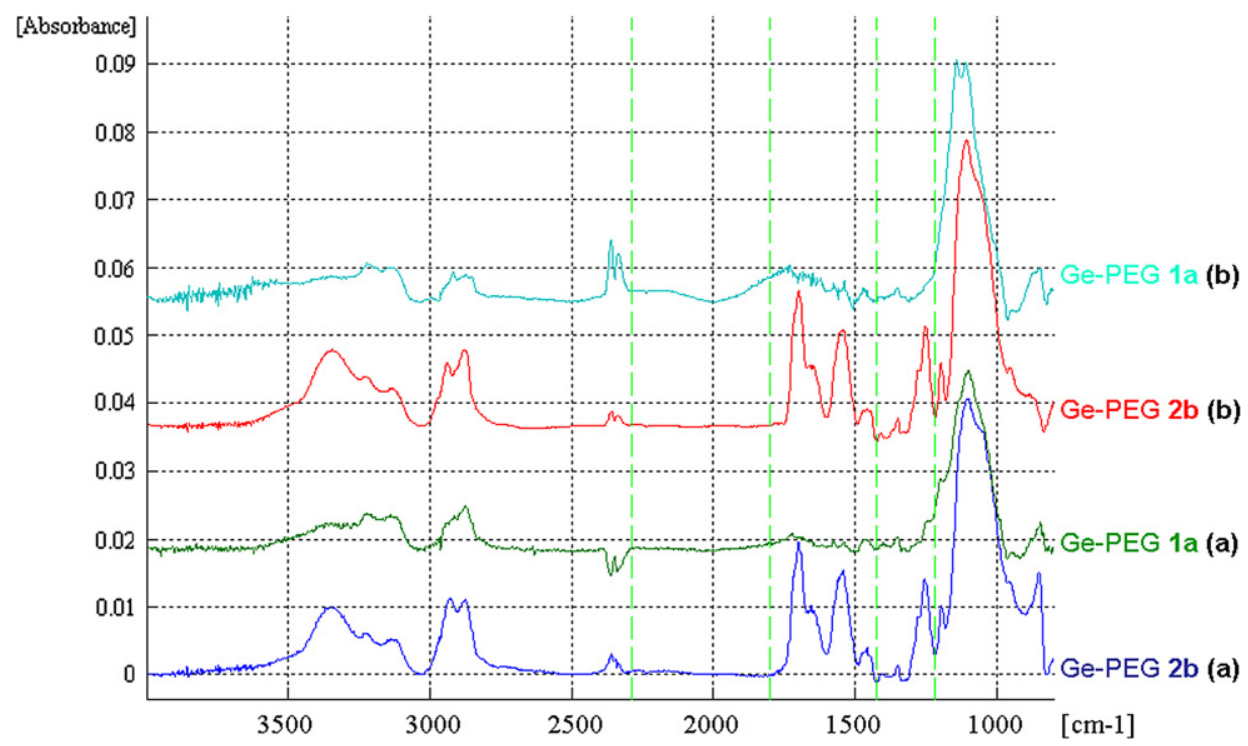

Fig. 3. ATR spectra of Ge-PEG 1a and Ge-PEG 2b; two independent manipulations (a) and (b) for each surface.

Table 3

Frequencies $\left(\mathrm{cm}^{-1}\right)$ and assignments of $\mathbf{2} \mathbf{b}$ dominant vibrational modes obtained by FTIR-ATR spectroscopy of Ge PEG $\mathbf{2 b}$ crystal.

\begin{tabular}{|c|c|c|}
\hline Frequency & Intensity $^{\mathrm{a}}$ & Assignment $^{\mathrm{b}}$ \\
\hline 3351 & $\mathrm{~m}$ & $\mathrm{~N}-\mathrm{H}$ st (carbamate) \\
\hline 3233 & $\mathrm{w}$ & oxidized crystal background \\
\hline 3132 & w & oxidized crystal background \\
\hline 2930 & $\mathrm{~m}$ & $\mathrm{O}-\mathrm{CH}_{2}, \mathrm{CH}_{2}$ st as \\
\hline 2879 & $\mathrm{~m}$ & $\mathrm{O}-\mathrm{CH}_{2}, \mathrm{CH}_{2}$ st sy \\
\hline 1699 & $\mathrm{~S}$ & $\mathrm{C}=\mathrm{O}$ st (carbamate) \\
\hline 1657 & $\mathrm{~m}$ & $\mathrm{C}=\mathrm{O}$ st (carbamate) \\
\hline 1565 & $\mathrm{~m}$ & $\mathrm{~N}-\mathrm{H} \delta$ (carbamate) \\
\hline 1548 & $\mathrm{~m}$ & $\mathrm{~N}-\mathrm{H} \delta$ (carbamate) \\
\hline 1463 & w & $\mathrm{O}-\mathrm{CH}_{2}, \mathrm{CH}_{2}$ bending \\
\hline 1404 & vw & $\mathrm{CH}_{3} \delta$ sy \\
\hline 1354 & w & $\mathrm{O}-\mathrm{CH}_{2}, \mathrm{CH}_{2}$ wagging \\
\hline 1278 & $\mathrm{~m}$ & (O)C-O st as (carbamate) \\
\hline 1261 & $\mathrm{~m}$ & $\mathrm{C}-\mathrm{N}$ st \\
\hline 1202 & $\mathrm{~m}$ & $\mathrm{CH}_{3}$ rocking mode \\
\hline 1101 & vs & $\mathrm{C}-\mathrm{O}-\mathrm{C}$ st as \\
\hline 1067 & vs & Si-O-C st \\
\hline 958 & $\mathrm{~m}$ & $\mathrm{C}-\mathrm{O}-\mathrm{C}$ st sy \\
\hline 856 & $\mathrm{~m}$ & $\mathrm{Si}-\mathrm{C}$ st \\
\hline
\end{tabular}

a vs (very strong), s (strong), m (medium), w (weak), vw (very weak).

b In agreement with Ref. [45] st = stretching, as = asymmetric, sy = symmetric.

region, a broad band centered at $1110 \mathrm{~cm}^{-1}$ (C-O-C asymmetric stretching) was visible. In the spectrum of Ge-PEG $\mathbf{2} \mathbf{b}$, the signals due to the $N$-(3-silyloxypropyl)-carbamate moiety superposed partially on the (EO)n pattern [34-38]. Main signals attribution of Ge-PEG $\mathbf{2 b}$ are given in Table 3.

Photografting of azide $\mathbf{5}$ on Ge-PEG $\mathbf{2 b}$ was conducted in the conditions described above for the Si element (Scheme 2, step ii). The so-called blank sample was coated with 5, not UV-irradiated, and rinsed similarly to the activated element Ge-PEG-NHS. FTIRATR spectra of both samples were recorded, with subtraction of the Ge-PEG 2b spectrum in order to clearly visualize the implanted NHS motif (Fig. 4). This gave a broad carbonyl band near $1710 \mathrm{~cm}^{-1}$ (ester and imide I) and another at $1540 \mathrm{~cm}^{-1}$ (imide II). The blank sample showed very weak NHS signals. Thus the "molecular clip" $\mathbf{5}$ is well fixed by photoactivation mainly.

Surface elemental compositions of native Ge-OH, Ge-PEG 2b and Ge-PEG-NHS were assayed by XPS (Table 4). The analysis of four spots of $\mathrm{Ge}-\mathrm{OH}$ showed a contamination with carbon (27$30 \%)$, nitrogen $(1-2 \%)$ and silicon $(\leqslant 0.4 \%)$. The atomic ratio $\mathrm{Ge} / \mathrm{O}$ was within 0.69 and 0.82 (entries 1-4). After silanization with $\mathbf{2 b}$,

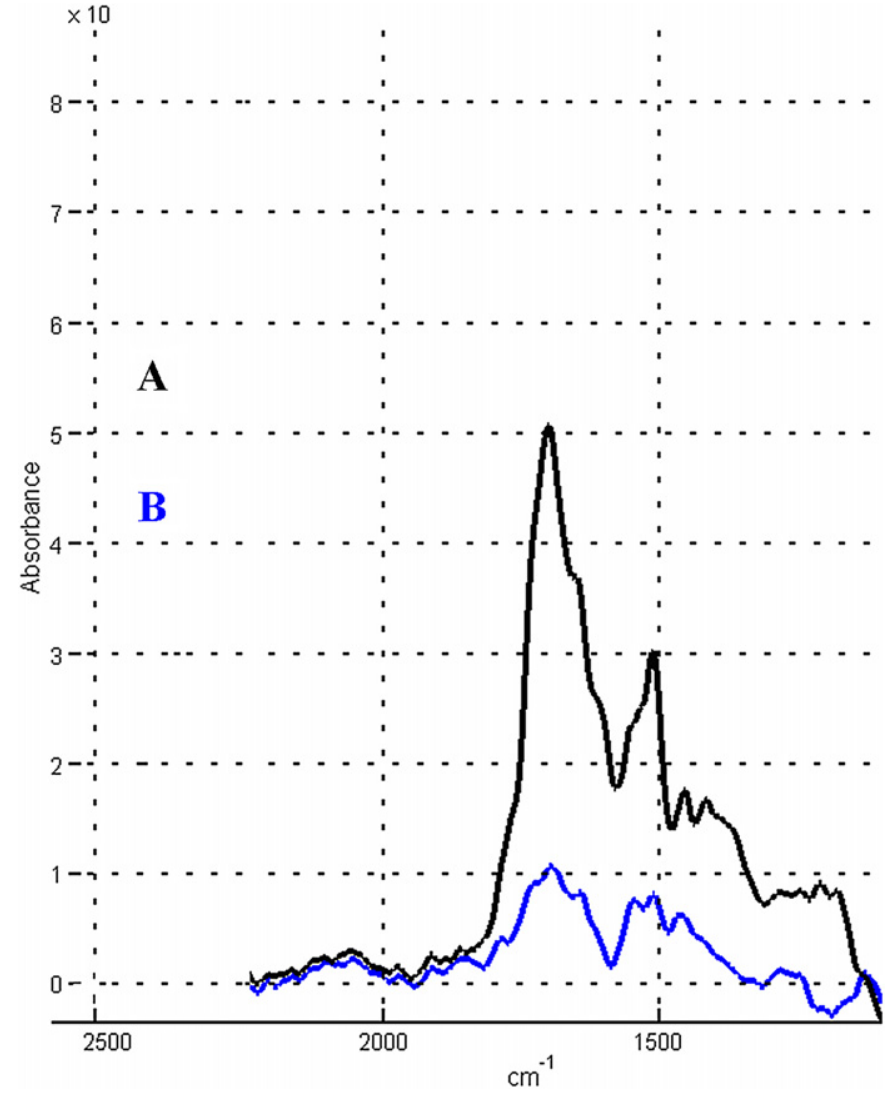

Fig. 4. Details of the ATR spectra of Ge-PEG-NHS (A) and blank (B) in the 1000$2000 \mathrm{~cm}^{-1}$ spectral domain. Spectra obtained by subtracting Ge-PEG $\mathbf{2 b}$.

the amounts of carbon, nitrogen and silicon ( $\mathrm{Si}$ from $\mathbf{2 b}$, but mainly contamination) increased, while the amounts of oxygen and germanium decreased. Due to the variable nitrogen contamination of the native element, the $\mathrm{N} / \mathrm{C}$ atomic ratios of two spots were respectively 0.057 and 0.082 , instead of 0.052 for an organic layer of theoretical formula $\mathrm{C}_{19} \mathrm{NO}_{9} \mathrm{Si}$ (entries 5-6). The experimental $\mathrm{O} / \mathrm{C}$ atomic ratios were 0.523 and 0.580 (theoretical value $=0.474$ ). The activated element Ge-PEG-NHS (three spots) showed an increase of the amount of nitrogen (entries 7-9). Substitution of NHS ester with 3,5-bis(trifluoromethyl)benzylamine (6) gave sample Ge-PEG- 
Table 4

XPS analysis of surface functionalized Ge ATR crystals.

\begin{tabular}{|c|c|c|c|c|c|c|c|}
\hline \multirow[t]{2}{*}{ Entry } & \multirow[t]{2}{*}{ Sample } & \multicolumn{6}{|c|}{ Elemental composition (atom\%) } \\
\hline & & $\mathrm{C}_{1 \mathrm{~s}}$ & $\mathrm{O}_{1 \mathrm{~s}}$ & $\mathrm{~N}_{1 \mathrm{~s}}$ & $\mathrm{Si}_{2 \mathrm{p}}$ & $\mathrm{F}_{1 \mathrm{~s}}$ & $\mathrm{Ge}_{3 p}$ \\
\hline 1 & $\mathrm{Ge}-\mathrm{OH}$ & 29.03 & 40.64 & 1.88 & 0.37 & 1 & 28.08 \\
\hline 2 & & 27.57 & 39.36 & 2.14 & 0.33 & l & 30.60 \\
\hline 3 & & 30.43 & 36.83 & 2.20 & 0.27 & I & 30.28 \\
\hline 4 & & 28.16 & 40.10 & 1.67 & 0.26 & l & 29.79 \\
\hline 5 & Ge-PEG 2b & 45.91 & 24.00 & 2.62 & 15.08 & 1 & 12.40 \\
\hline 6 & & 41.79 & 24.25 & 3.48 & 12.78 & i & 17.70 \\
\hline 7 & Ge-PEG-NHS & 42.20 & 25.67 & 4.77 & 1.24 & l & 26.12 \\
\hline 8 & & 37.06 & 29.89 & 4.42 & 2.19 & 1 & 26.45 \\
\hline 9 & & 60.96 & 16.45 & 3.74 & 0.91 & 1 & 17.94 \\
\hline 10 & Ge-PEG-F6 & 41.53 & 24.95 & 3.81 & 3.96 & 1.53 & 24.23 \\
\hline 11 & & 40.55 & 23.41 & 5.48 & 1.58 & 1.36 & 27.61 \\
\hline 12 & & 53.63 & 19.68 & 3.96 & 1.59 & 1.71 & 19.42 \\
\hline
\end{tabular}

F6 (Scheme 2, step iii). XPS analysis (three spots) revealed the presence of fluorine atoms (1.4 to $1.7 \%$ ). A substitution rate between $12 \%$ and $22 \%$ was calculated (see supplementary material). Deconvolution of the $C_{1 s}$ peak of Ge-PEG-NHS and Ge-PEG-F6 confirmed the stepwise construction of a functionalized organic layer on the Ge surface (see supplementary material).

\subsection{Adsorption/fixation of proteins on the activated elements}

The pre-requisite for using $\mathrm{Si} / \mathrm{Ge}-\mathrm{PEG}$ elements in biosensor construction, is the stability of the organic covering under the conditions usually applied for measuring "receptor-ligand" interactions. This has been controlled by FTIR-ATR spectroscopy under PBS flux at $25^{\circ} \mathrm{C}$ over $220 \mathrm{~min}$. Spectra of Si-PEG 1b recorded in negative mode in function of time showed the progressive etching of the surface by the disappearance of the $\mathrm{CH}$ stretching bands in the $2800-3000 \mathrm{~cm}^{-1}$ region (see Fig. 2). After $220 \mathrm{~min}$, the organic layer created from commercial silane $\mathbf{1 b}$ was almost totally removed, probably by hydrolysis of the interface $\mathrm{Si}-\mathrm{O}$ bonds that liberates the PEG molecules [25].

The same test performed with Ge-PEG $2 \mathbf{b}$ demonstrated the remarkable stability of our home-made construction. After several hours under PBS flux $(20 \mu \mathrm{L} / \mathrm{min})$ at $25^{\circ} \mathrm{C}$, the FTIR-ATR spectrum of Ge-PEG 2b was identical to that of the starting material (see supplementary material).

We used BlaR-CTD as model of receptor for controlling the protein grafting on the activated device Ge-PEG-NHS and the stability of the resulting biosensor under PBS flux, on the one hand, and the protein repulsive effect of Ge-PEG $\mathbf{2 b}$ device (i.e., the blank sample prepared in parallel with the activated one), on the other hand. BlaR is a membrane-bound penicillin receptor of Bacillus licheniformis 749I, that is able to detect the presence of antibiotics outside the cell during the production of BlaR $\beta$-lactamase (production inducible by $\beta$-lactam antibiotics) [41]. The C-terminal extracellular domain, namely BlaR-CTD (residues 346-6001) [42] acts as a penicillin sensor recognizing the majority of $\beta$-lactam antibiotics; therefore it can be used to detect this class of drugs [43]. BlaR-CTD receptor was fixed on the activated device Ge-PEG-NHS by passing the protein solution $\left(3 \mathrm{~h}, 25^{\circ} \mathrm{C}\right)$ over the ATR crystal; this fixation was monitored by FTIR spectroscopy (see supplementary material). Comparatively to the blank sample, the anchorage of the protein was clearly visible by the appearance of an amide II band at $1550 \mathrm{~cm}^{-1}$, and the reaction occurred rapidly (maximum reached after $1 \mathrm{~h}$ ). This band has been considered as the protein signature; it derives mainly from the in plane $\mathrm{N}-\mathrm{H}$ bending of the amide bonds [9]. The construction was stable under PBS flux. Fig. 5 compares the integrated absorbance of amide I and amide II bands for the Ge-PEG + BlaR-CTD and Ge-PEG 2b (blank) devices under PBS washing (integration between 1470 and $1700 \mathrm{~cm}^{-1}$ ).

\section{Conclusion}

We have designed and validated an original thin organic covering (of about $20 \AA$ depth) for the surface functionalization of a $\mathrm{Ge}$ crystal ATR device. The covalent grafting of 2,5,8,11,14,17,20-heptaoxadocosan-22-yl-3-(triethoxysilyl) propylcarbamate $(\mathbf{2 b})$ on the previously oxidized Ge surface led to a stable organic layer, resistant to etching under PBS flux, for several hours. Most probably, the device surface, featuring highly sensitive Ge-O-Si-O ether bonds, is protected from hydrolysis by the hydrophobic barrier resulting from the hydrogen bonds network created between the carbamate functions of neighbouring chains (Fig. 6, part (a)). Hence,

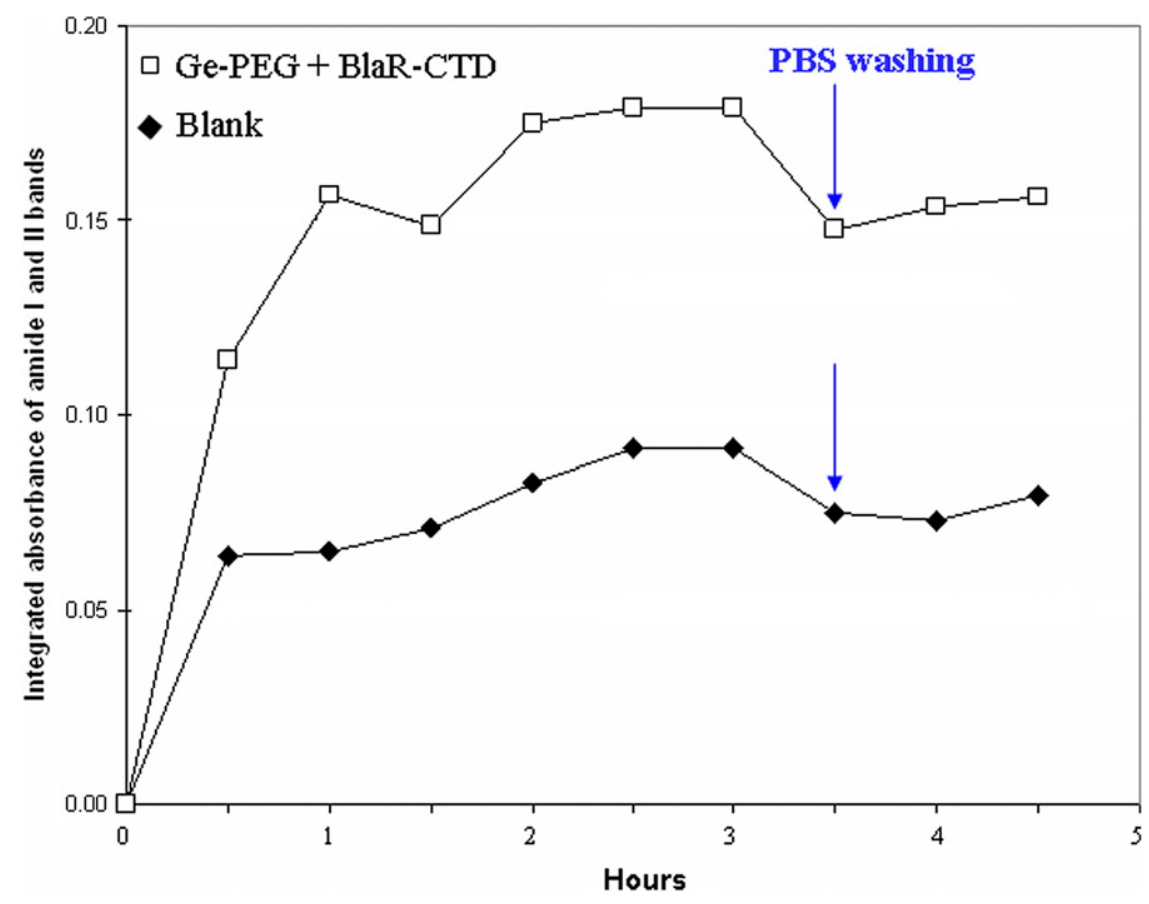

Fig. 5. Evolution of amide I + amide II absorbances during BlaR-CTD fixation on Ge-PEG 2b and stability of the biosensor under PBS washing. 


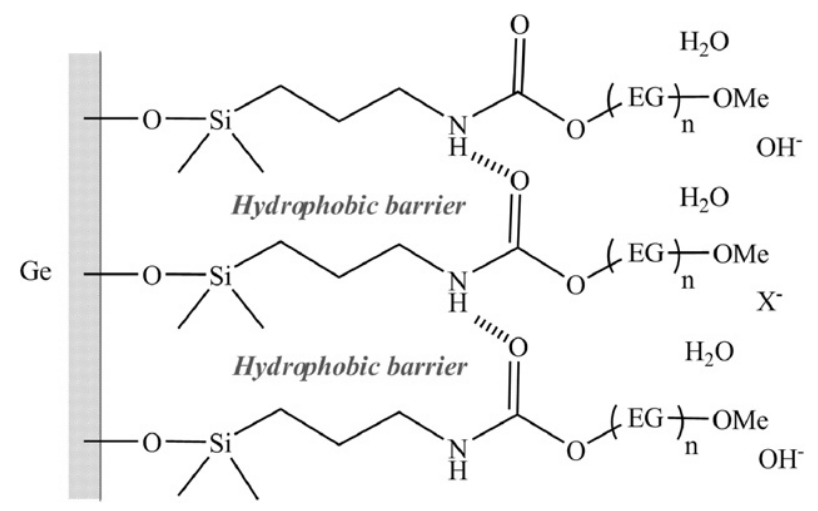

(a)

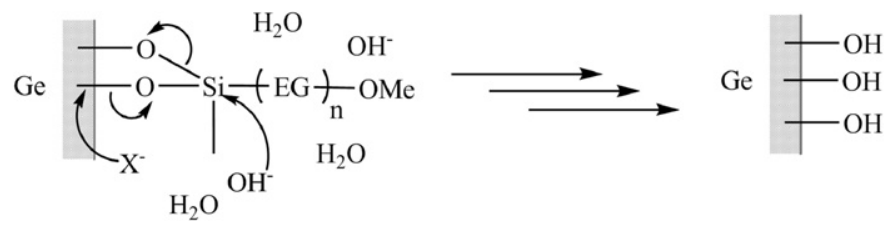

$(\mathrm{HO})_{3} \mathrm{Si}-\mathrm{EG} \underset{\mathrm{n}}{+} \mathrm{OMe}$

(b)

Fig. 6. Stability of the amphiphilic organic covering (a) versus hydrophilic covering (b); $\mathrm{X}^{-}=\mathrm{Cl}^{-}$, phosphate anions, etc.

very short alkyl segments $\left(-\left(\mathrm{CH}_{2}\right)_{3}-\right)$ could replace the long chains $\left(-\left(\mathrm{CH}_{2}\right)_{n}-\right.$ with $\left.n \geqslant 11\right)$ traditionally used to make hydrophobic self-assembled monolayers (SAMs) on surfaces [44]. The exposed hydrophilic PEG segments of our amphiphilic covering $\mathbf{2 b}$ are well protein repulsive as exemplified with BlaR-CTD receptor. A similar effect could not be evidenced in the case of Ge devices grafted with commercial PEG molecule 1 (Fig. 6, part (b)), because surface etching rapidly occurred under PBS flux (hydrolysis by $\mathrm{OH}^{-}$and/or nucleophilic substitution by $\mathrm{Cl}^{-}$, phosphate anions).

Photografting of "molecular clip" $\mathbf{5}$ onto the Ge-PEG 2b surface provided the activated device (Ge-PEG-NHS), ready for the anchorage of any biomacromolecule of interest. All the steps of the previous construction could be easily monitored by FTIR-ATR spectroscopy, within a broad spectral window allowing structural analysis. Moreover, background subtraction at each step (organic covering, photoactivation, receptor coupling) facilitates the identification of small ligands. We have controlled the stability of Ge-PEGNHS under different storage conditions. In the absence of moisture, the device is stable during several months (storage in the dark, at $0{ }^{\circ} \mathrm{C}$ ); its whole surface or selected lanes can be grafted with a particular receptor, on request (data not shown).

This work laid the foundations for the construction of novel FTIR-biosensors. Application in the field of $\beta$-lactam antibiotics (penicillins) detection is currently under investigation.

\section{Acknowledgments}

This work was generously supported by the Ministère de la Région Wallonne, Belgium (Projects BIA-ATR and MED-ATR, contracts nos. $0516040,0516263,0516264,0516265)$. Thanks are due to D. Seveno (UMH, CRMM) for molecular mechanics simulation of the 2b silane molecule, and to B. Joris (CIP, ULg), P. Tulkens (FARM, UCL) and M. Genêt (CIFA, UCL) for stimulating discussions V. Pourcelle is acknowledged for his help in manuscript preparation. J.M.B., F.H. and E.G. are Senior Research Associates of the FRS-FNRS (Fonds National de la Recherche Scientifique, Belgium).

\section{Supplementary material}

The online version of this article contains additional supplementary material.

Please visit DOI: 10.1016/j.jcis.2008.12.045.

\section{References}

[1] S. Andreescu, O.A. Sadik, Pure Appl. Chem. 76 (2004) 861.

[2] K. Onodera, A. Hirano-Iwata, K.-I. Miyamoto, Y. Kimura, M. Kataoka, Y. Shinohara, M. Niwano, Langmuir 23 (2007) 12287.

[3] J. Lahiri, L. Isaacs, J. Tien, G.M. Whitesides, Anal. Chem. 71 (1999) 777.

[4] K. Inamori, M. Kyo, Y. Nishiya, Y. Inoue, T. Sonoda, E. Kinoshita, T. Koike, Y. Katayama, Anal. Chem. 77 (2005) 3979.

[5] L. Dreesen, C. Silien, C. Volcke, Y. Sartenaer, A. Thiry Paul, A. Peremans, J. Grugier, J. Marchand-Brynaert, A. Brans, S. Grubisic, B. Joris, ChemPhysChem 8 (2007) 1071.

[6] E. Goormaghtigh, V. Raussens, J.-M. Ruysschaert, Biochim. Biophys. Acta Rev. Biomembr. 1422 (1999) 105.

[7] C. Vigano, J.-M. Ruysschaert, E. Goormaghtigh, Talanta 65 (2005) 1132.

[8] M. Voue, E. Goormaghtigh, F. Homble, J. Marchand-Brynaert, J. Conti, S. Devouge, J. De Coninck, Langmuir 23 (2007) 949.

[9] A. Goldsztein, A. Aamouche, F. Homblé, M. Voué, J. De Coninck, S. Devouge, J. Marchand-Brynaert, Biosens. Bioelectron. (2008), in press; doi: 10.1016/ j.bios.2008.09.013.

[10] J.B. Brzoska, I.B. Azouz, F. Rondelez, Langmuir 10 (1994) 4367.

[11] R.P. Sperline, J.S. Jeon, S. Raghavan, Appl. Spectrosc. 49 (1995) 1178.

[12] F.G. Haibach, A. Sanchez, J.A. Floro, T.M. Niemczyk, Appl. Spectrosc. 56 (2002) 398.

[13] J.M. Buriak, Chem. Rev. 102 (2002) 1271.

[14] R. Chen, S.F. Bent, Chem. Mater. 18 (2006) 3733.

[15] S. Devouge, C. Salvagnini, J. Marchand-Brynaert, Bioorg. Med. Chem. Lett. 15 (2005) 3252.

[16] S.I. Jeon, J.H. Lee, J.D. Andrade, P.G. De Gennes, J. Colloid Interface Sci. 142 (1991) 149.

[17] G.M. Harbers, K. Emoto, C. Greef, S.W. Metzger, H.N. Woodward, J.J. Mascali, D.W. Grainger, M.J. Lochhead, Chem. Mater. 19 (2007) 4405.

[18] L. Li, S. Chen, J. Zheng, D. Ratner Buddy, S. Jiang, J. Phys. Chem. B 109 (2005) 2934.

[19] S.-W. Lee, P.E. Laibinis, Biomaterials 19 (1998) 1669.

[20] S. Herrwerth, W. Eck, S. Reinhardt, M. Grunze, J. Am. Chem. Soc. 125 (2003) 9359.

[21] S. Sharma, R.W. Johnson, T.A. Desai, Langmuir 20 (2004) 348.

[22] S. Onclin, B.J. Ravoo, D.N. Reinhoudt, Angew. Chem. Int. Ed. 44 (2005) 6282.

[23] A. Roosjen, J. de Vries, H.C. van der Mei, W. Norde, H.J. Busscher, J. Biomed. Mater. Res. B Appl. Biomat. 73B (2005) 347.

[24] A. Wang, H. Tang, T. Cao, S.O. Salley, K.Y.S. Ng, J. Colloid Interface Sci. 291 (2005) 438.

[25] C.M. Dekeyser, C.C. Buron, K. Mc Evoy, C.C. Dupont-Gillain, J. MarchandBrynaert, A.M. Jonas, P.G. Rouxhet, J. Colloid Interface Sci. 324 (2008) 118.

[26] N.T. Flynn, T.N.T. Tran, M.J. Cima, R. Langer, Langmuir 19 (2003) 10909.

[27] T. Tsukagoshi, Y. Kondo, N. Yoshino, Colloids Surf. B Biointerfaces 54 (2007) 82

[28] R. Valiokas, S. Svedhem, M. Ostblom, S.C.T. Svensson, B. Liedberg, J. Phys. Chem. B 105 (2001) 5459.

[29] B.D. Gates, Q. Xu, M. Stewart, D. Ryan, C.G. Willson, G.M. Whitesides, Chem Rev. 105 (2005) 1171. 
[30] S. Watanabe, K. Usui, K.-Y. Tomizaki, K. Kajikawa, H. Mihara, Mol. Biosyst. 1 (2005) 363.

[31] B.T. Houseman, M. Mrksich, J. Org. Chem. 63 (1998) 7552.

[32] V. Pourcelle, S. Devouge, M. Garinot, V. Preat, J. Marchand-Brynaert, Biomacromolecules 8 (2007) 3977.

[33] M. Voue, S. Semal, J. De Coninck, Langmuir 15 (1999) 7855.

[34] L. Malysheva, Y. Klymenko, A. Onipko, R. Valiokas, B. Liedberg, Chem. Phys Lett. 370 (2003) 451

[35] D.J. Vanderah, J. Arsenault, H. La, R.S. Gates, V. Silin, C.W. Meuse, G. Valincius, Langmuir 19 (2003) 3752.

[36] L. Malysheva, A. Onipko, R. Valiokas, B. Liedberg, J. Phys. Chem. A 109 (2005) 7788.

[37] L. Malysheva, A. Onipko, R. Valiokas, B. Liedberg, J. Phys. Chem. B 109 (2005) 13221.
[38] L. Malysheva, A. Onipko, R. Valiokas, B. Liedberg, Appl. Surf. Sci. 246 (2005) 372.

[39] C. Salvagnini, A. Roback, M. Momtaz, V. Pourcelle, J. Marchand-Brynaert, J. Biomater. Sci. Polym. Ed. 18 (2007) 1491.

[40] S. Biltresse, D. Descamps, C. Henneuse-Boxus, J. Marchand-Brynaert, J. Polym. Sci. Part A Polym. Chem. 40 (2002) 770.

[41] A. Philippon, J. Dusart, B. Joris, J.M. Frere, Cell. Mol. Life Sci. 54 (1998) 341.

[42] F. Kerff, P. Charlier, M.-L. Colombo, E. Sauvage, A. Brans, J.-M. Frere, B. Joris, E. Fonze, Biochemistry 42 (2003) 12835.

[43] V. Duval, M. Swinnen, S. Lepage, A. Brans, B. Granier, C. Franssen, J.-M. Frere, B. Joris, Mol. Microbiol. 48 (2003) 1553.

[44] R. Jogireddy, I. Zawisza, G. Wittstock, J. Christoffers, Synlett (2008) 1219.

[45] E. Pretsch, P. Bühlmann, C. Affolter, Tables of Spectral Data, Structure Determination of Organic Compounds, third ed., Springer-Verlag, Berlin, 2000. 